\title{
AUTEKOLOGI TUMBUHAN OBAT Selaginella doederleinii Hieron DI SEBAGIAN KAWASAN HUTAN BUKIT POHEN CAGAR ALAM BATUKAHU, BEDUGUL BALI (Autecology of Traditional Medicine Plant of Selaginella doederleinii Hieron in Some Areas of Mount Pohen Forest Batukahu Nature Reserve Bedugul, Bali)*
}

\author{
Sutomo dan/and Dini Fardila \\ UPT Balai Konservasi Tumbuhan Kebun Raya "Eka Karya" Bali-LIPI \\ Candikuning, Baturiti, Tabanan-Bali 82191; eml: sutomo.uwa@gmail.com \\ * Diterima : 23 Oktober 2012; Disetujui : 21 Februari 2013
}

\begin{abstract}
Autecological study of spike-moss in its natural habitat was conducted on October 2010 in Pohen Hill, Batukahu Nature Reserve, Bedugul, Bali. Two $100 \mathrm{~m}$ transect lines was aligned perpendicular from forest edge to interior. In each transect, five sampling plots of $5 \mathrm{~m} \times 5 \mathrm{~m}$ were placed at 0, 20, 40, 60, and $80 \mathrm{~m}$ point from forest edge. Plant species abundance as well as microclimate and landscape variables such as temperature, humidity, light intensity, slope, and altitude were recorded in each sampling plot. Non metric Multidimensional Scaling (NMDS) ordination analysis was used to identify distribution patterns and association patterns of spike-moss with other species in sampling plots. Correlation between environmental variables and spike-moss abundance data was assessed using Spearman bivariate correlation analysis. NMDS ordination results indicated that there were differences in plant composition from edge to forest interior. The same pattern was seen in spike-moss abundance, which tended to increase when the observation plots moved to the forest interior. Spearman bivariate correlation analysis showed that humidity, altitude, and slope were positively correlated with spike-moss abundance, while temperature was negatively correlated. These results suggested that differences in spike-moss abundance in sampling plots were associated with environmental gradients along edge to forest interior. These results also confirmed that spike-moss is often found in humid and wet areas with steep slopes. NMDS ordination also showed an association between spike-moss with herbaceous plant Oplismenus sp., which somehow indicated interaction between the two species.
\end{abstract}

Keywords: Autecology, Selaginella doederleinii, environmental factors, NMDS ordination, Pohen Hill

\begin{abstract}
ABSTRAK
Penelitian ini untuk mengkaji autekologi paku cakar ayam Selaginella doederleinii Hieron di habitat alaminya telah dilakukan pada bulan Oktober 2010 di kawasan hutan Bukit Pohen, Cagar Alam Batukahu, Bedugul, Bali. Sebanyak dua transek garis sepanjang $100 \mathrm{~m}$ dibentangkan dari tepi ke arah interior hutan. Pada masing-masing transek diletakkan lima plot pengamatan berukuran $5 \mathrm{~m} \times 5 \mathrm{~m}$ pada titik $0 \mathrm{~m}, 20 \mathrm{~m}, 40$ m, $60 \mathrm{~m}$, dan $80 \mathrm{~m}$ dari tepi hutan. Kelimpahan jenis-jenis tumbuhan serta variabel mikroklimat dan lansekap seperti suhu, kelembaban udara, intensitas cahaya, slope, dan altitude dicatat pada tiap plot pengamatan. Analisis ordinasi Non-Metric Multidimensional Scaling (NMDS) dilakukan untuk mengidentifikasi pola distribusi serta pola asosiasi paku cakar ayam dengan jenis lain pada plot pengamatan. Korelasi antara variabel lingkungan dengan kelimpahan paku cakar ayam dikaji dengan analisis korelasi Spearman bivariat. Hasil ordinasi NMDS menunjukkan bahwa terdapat perbedaan komposisi vegetasi pada tiap plot pengamatan, mulai dari tepi ke arah interior hutan. Hal yang sama juga terlihat pada kelimpahan paku cakar ayam yang semakin bertambah seiring dengan semakin masuknya plot pengamatan ke interior hutan. Analisis korelasi Spearman bivariat menunjukkan bahwa kelembaban udara, slope, dan altitude berkorelasi positif dengan kelimpahan paku cakar ayam, sedangkan suhu berkorelasi negatif. Hal ini menunjukkan bahwa perbedaan kelimpahan paku cakar ayam pada plot-plot pengamatan terkait dengan adanya gradien faktor lingkungan antara daerah tepi dengan interior hutan. Hasil ini juga menegaskan bahwa paku cakar ayam banyak dijumpai pada lokasi yang lembab dan basah dengan kelerengan yang terjal. Berdasarkan analisis ordinasi NMDS juga diketahui bahwa terdapat kecenderungan paku cakar ayam untuk berasosiasi dengan tumbuhan herba Oplismenus sp., yang mengindikasikan adanya interaksi di antara keduanya.
\end{abstract}

Kata kunci: Autekologi, Selaginella doederleinii Hieron, faktor lingkungan, ordinasi NMDS, Bukit Pohen 


\section{PENDAHULUAN}

Berbagai sistem pengobatan tradisional telah berkembang berdasarkan kearifan lokal dan potensi tumbuhan di masing-masing daerah di Indonesia. Di Bali, kekayaan budaya masyarakat Bali mengenai pengobatan tradisional (indigenous medicinal knowledge) tercatat dalam manuskrip lontar usada Bali yang berisi sistem pengobatan, bahan obat, dan cara pengobatan tradisional yang memiliki arti dan posisi penting dalam sistem pengobatan tradisional di Bali. Kata usada berasal dari ausadhi (Sanskerta) yang berarti tumbuh-tumbuhan yang mengandung khasiat obat-obatan. Tumbuhan obat adalah kelompok tumbuhan yang umumnya digunakan sebagai bahan atau bahan baku obat (Nala, 1996; Sutomo, 2007; Sutomo et al., 2009).

Salah satu tumbuhan obat usada adalah paku cakar ayam atau Selaginella doederleinii Hieron. Paku cakar ayam adalah salah satu anggota dari Divisi Pteridophyta dari suku Selaginellaceae. Tumbuhan ini memiliki batang tegak dengan tinggi sekitar 15-35 cm dan akarnya keluar pada percabangan. Jenis ini memiliki daun yang kecil-kecil dengan panjang empat-lima $\mathrm{mm}$, lebar dua $\mathrm{mm}$, berbentuk jorong dengan yang ujung meruncing serta pangkal yang rata. Salah satu ciri khas lainnya adalah dari warna daun, di mana di bagian atas hijau tua sedangkan bagian bawah hijau muda. Daun tersusun di kiri-kanan batang induk sampai ke percabangannya yang menyerupai cakar ayam dengan sisik-sisiknya (Dalimartha, 1999). Paku cakar ayam mempunyai habitus terna, merayap, dan sedikit tegak. Batang bulat, liat, bercabang-cabang menggarpu, tanpa pertumbuhan sekunder, dan putih kecoklatan. Akarnya serabut dan muncul dari batang yang berdaun dan berwarna coklat kehitaman (Hutapea, 1999). Paku cakar ayam dilaporkan mengandung alkaloid, saponin, dan phytosterol. Tumbuhan obat ini berkhasiat untuk menghilangkan panas, melancarkan aliran darah, antitoksik, antineoplasma, penghenti pendarahan (hemostatis) serta menghilangkan bengkak. Selain itu paku cakar ayam juga berkhasiat untuk mengatasi batuk, infeksi saluran nafas, radang paru, hepatitis, diare, keputihan, tulang patah, pendarahan, dan kanker (Dalimartha, 1999).

Obat tradisional adalah aset bangsa Indonesia yang terkenal kaya akan keanekaragaman hayatinya. Hutan pegunungan menjadi salah satu tempat "sanctuary" terakhir dari keanekaragaman hayati yang tersisa di Pulau Bali, seperti halnya juga di Pulau Jawa. Saat ini diperkirakan seki$\operatorname{tar} 31.817,75$ ha atau 25\% dari luas keseluruhan hutan daratan di Bali, yaitu 127.271,01 ha, mengalami konversi fungsi lahan. Perubahan fungsi lahan hutan tersebut disebabkan beberapa hal, antara lain perambahan kawasan hutan oleh kelompok-kelompok masyarakat yang berdiam di dekat hutan dan penggunaan kawasan hutan untuk pembangunan di luar sektor kehutanan, penebangan liar, dan kebakaran (Anonim, 2005).

Cagar Alam (CA) Batukahu terdiri dari fragmen tiga fragmen kawasan yang terletak berdekatan tetapi tidak bersinggungan satu sama lain. Ketiganya adalah CA Batukahu I di Bukit Tapak seluas 810,4 ha; CA Batukahu II di Gunung Lesong seluas 564,2 ha; dan CA Batukahu III di Bukit Pohen seluas 388,2 ha. Di sekeliling kawasan ini terdapat kawasan penyangga berupa hutan lindung yang merupakan lembah dari ketiga gunung tersebut. Saat ini diyakini berbagai jenis tumbuhan berpotensi obat tumbuh di Bukit Pohen, akibat dari kemarau panjang dan gangguan antropogenik, sekitar 30,5 ha hutan di Bukit Pohen habis terbakar di tahun 1994 (Sutomo, 2011). Dengan meningkatnya berbagai kepentingan pembangunan terhadap kawasan ini, terutama berupa alih fungsi lahan hutan menjadi permukiman, perkebunan bahkan pembangunan stasiun pembangkit listrik tenaga panas bumi (PLTP), dikhwatirkan akan 
banyak pula jenis-jenis tumbuhan berpotensi obat yang punah.

Salah satu bentuk upaya awal konservasi jenis adalah dengan melakukan studi autekologi jenis tersebut di habitat alaminya. Studi auteknologi Selaginella doederleinii Hieron melihat hubungan lingkungan tempat hidupnya dari faktor abiotik dan biotiknya, mengingat kajian autekologi tumbuhan obat di kawasan Bedugul masih sangat jarang dilakukan. Salah satu kajian autekologi tumbuhan obat yang pernah dilakukan di Bukit Tapak kawasan CA Batukahu terhadap jenis tumbuhan obat pronojiwo (Euchresta horsfieldii (Lesch.) Benn) (Sutomo \& Mukaromah, 2010). Penelitian autekologi jenis tumbuhan obat paku cakar ayam (Selaginella doederleinii Hieron) di Bukit Pohen CA Batukahu bertujuan untuk meningkatkan upaya konservasi in-situ dan ex-situ di Kebun Raya Eka Karya Bali.

\section{BAHAN DAN METODE}

\section{A. Waktu dan Lokasi Penelitian}

Penelitian dilakukan pada bulan Oktober 2010 di kawasan hutan Bukit Pohen, salah satu situs dari CA Batukahu. CA Batukahu terletak di Desa Candikuning, Kecamatan Baturiti, Kabupaten Tabanan, dan di Desa Asah Munduk, Kecamatan Banjar, Kabupaten Buleleng. Secara geografis terletak pada $8^{\circ} 10^{\prime}-8^{\circ} 23^{\prime}$ LS dan $115^{\circ} 02^{\prime}-115^{\circ} 15^{\prime}$ BT dengan jarak \pm 55 km utara Kota Denpasar dan \pm 30 km selatan Kota Singaraja (Gambar 2).

\section{B. Bahan dan Alat Penelitian}

Bahan yang digunakan dalam penelitian ini adalah tumbuhan paku cakar ayam di kawasan hutan Bukit Pohen (Gambar 1). Alat yang digunakan dalam penelitian ini di antaranya adalah GPS GARMIN GPS 76 CSX dan peralatan pengukuran data mikroklimat seperti sling psycrometer, luxmeter, dan clinometer.

\section{Metode Penelitian}

\section{Pengambilan Sampel}

Pengambilan sampel dilakukan dengan cara membuat dua transek dimulai dari tepi jalan stasiun Pembangkit Listrik Tenaga Panas Bumi (PLTPB) menuju ke dalam hutan di sebagian kawasan hutan Bukit Pohen, dengan jarak antar transek $50 \mathrm{~m}$ (Gambar 2). Pada tiap transek dibuat plot pengamatan berukuran $5 \mathrm{~m}$ x $5 \mathrm{~m}$. Jarak antar plot sekitar $20 \mathrm{~m}$ dengan jarak dari titik awal (tepi jalan stasiun PLTPB) sampai ke plot paling dalam hutan (interior hutan) adalah $0 \mathrm{~m}, 20 \mathrm{~m}, 40 \mathrm{~m}, 60$ $\mathrm{m}$, dan $80 \mathrm{~m}$, sehingga total didapatkan 10 plot. Keterwakilan sampel untuk area studi sebelumnya didapatkan dengan melakukan analisis species-accumulation plot. Jumlah individu paku cakar ayam dan jenis tumbuhan penutup tanah lainnya dalam tiap plot dihitung dengan menggunakan counter. Pada tiap plot juga dilakukan pengukuran variabel mikroklimat dan lansekap seperti intensitas cahaya (dengan luxmeter), suhu udara, kelembaban udara (dengan sling psychrometer), serta altitude/ketinggian tempat (dengan GPS) dan kelerengan/slope (dengan clinometer). Semua pengukuran mikroklimat dilakukan dengan ulangan sebanyak dua kali dan diukur pada jam tertentu, yaitu antara jam 9.00-11.00 pagi.

\section{Analisis Data}

Di dalam kegiatan studi lapangan, seringkali sebaran data yang didapatkan tidak mengikuti sebaran data normal. Untuk itu pada kegiatan ekologi lapangan, lebih tepat jika dilakukan analisis nonparametrik, dan dengan banyaknya jumlah sampel dan plot yang perlu dianalisis bersamaan maka analisis multivariate menjadi penting. Salah satu analisis multivariate yang umum digunakan adalah ordinasi. Analisis ordinasi (Non-Metric Multidimensional Scaling/NMDS) dengan menggunakan software ekologi PRIMER (Clarke \& Gorley, 2005) digunakan untuk mengidentifikasi pola 


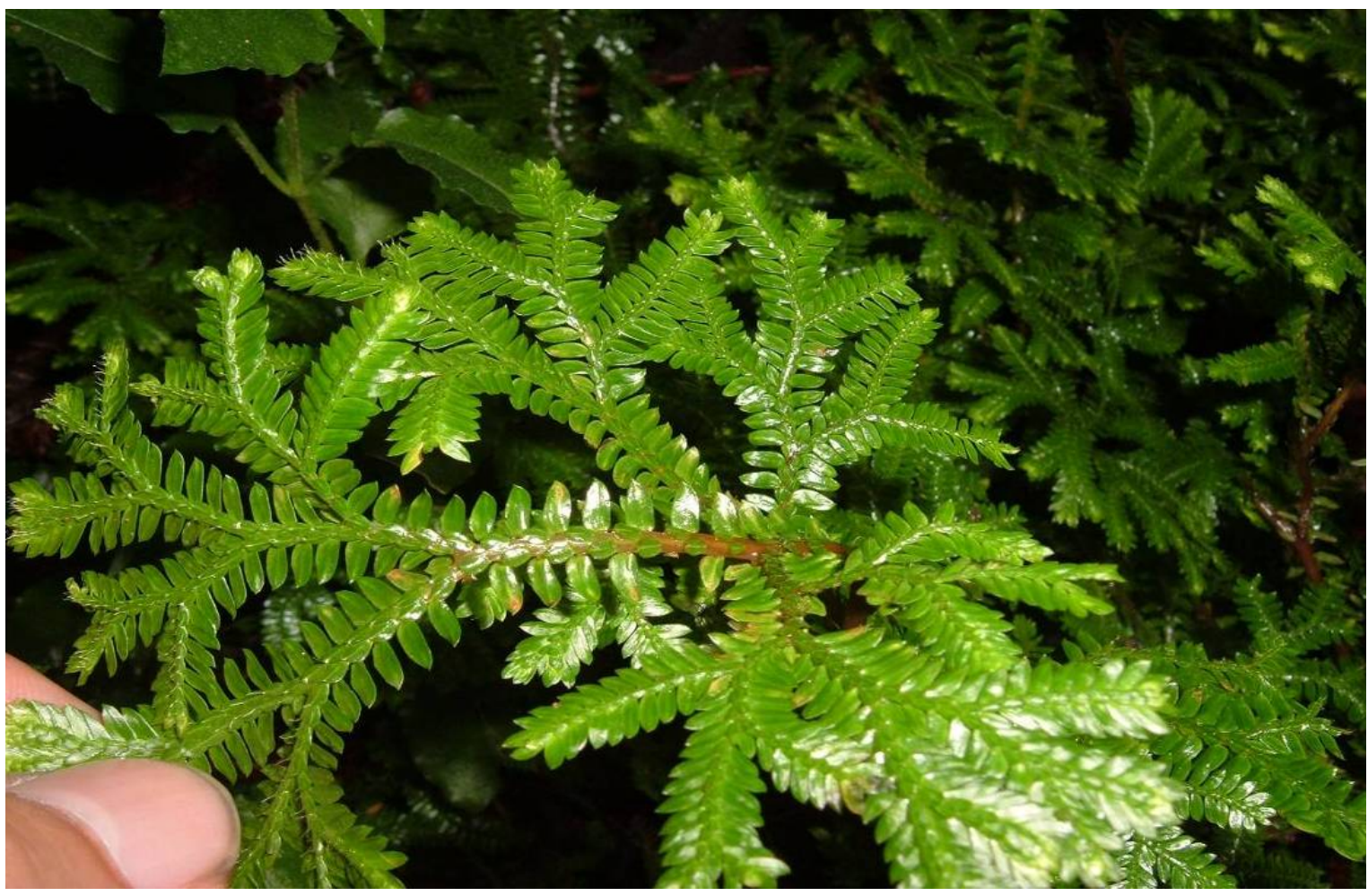

Gambar (Figure) 1. Paku cakar ayam (Selaginella doederleinii) di sekitar areal hutan konservasi di Kebun Raya Eka Karya Bali (Spike-moss (Selaginella doederleinii) in forest area of Eka Karya Bali Botanical Garden)

115\%'50"E

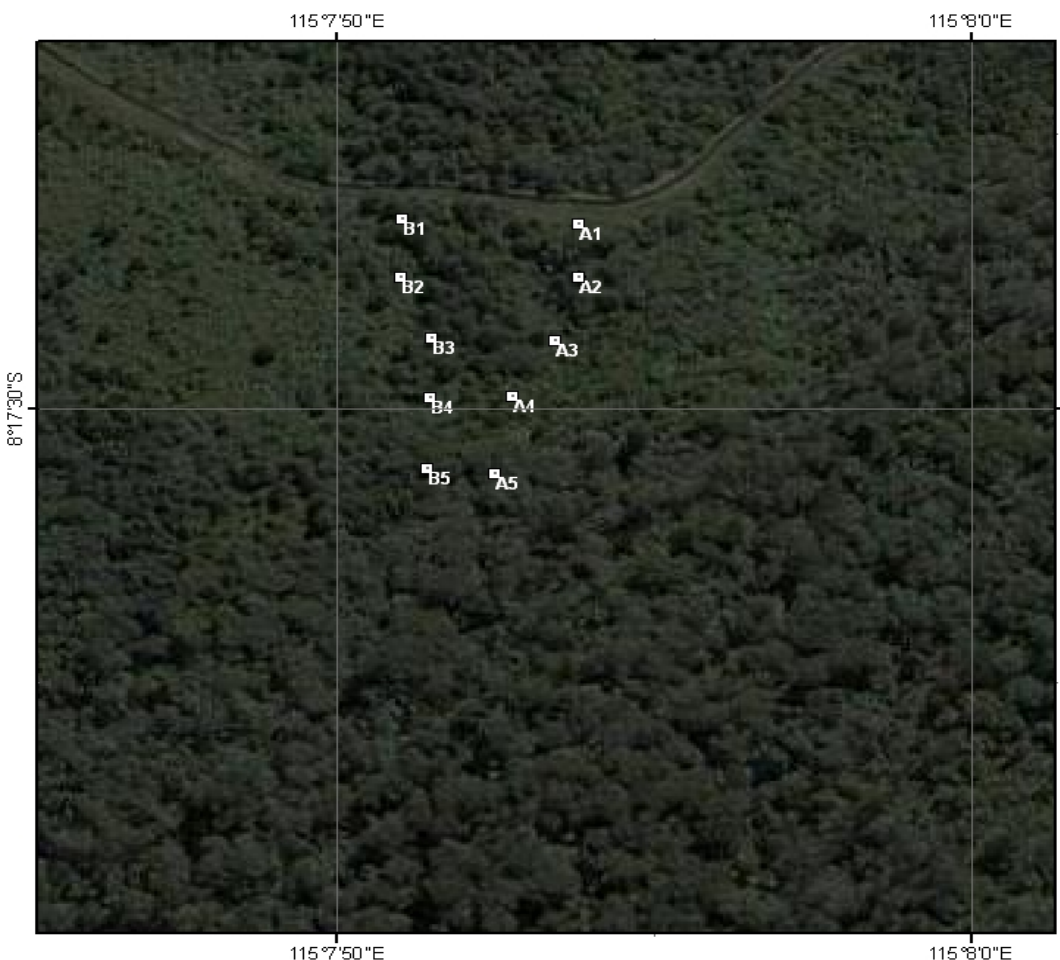

115 व'0"E

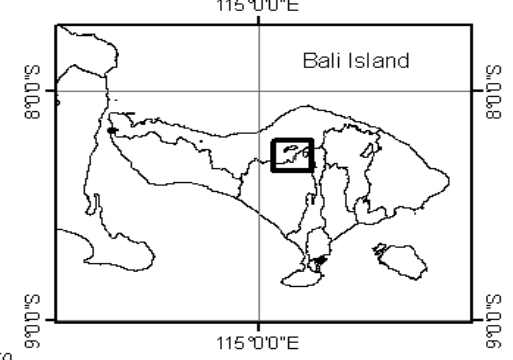

酸
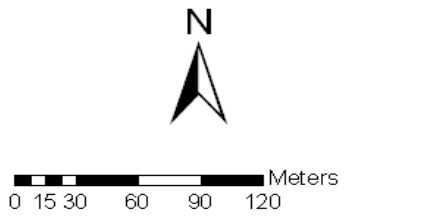

Gambar (Figure) 2. Lokasi penelitian dan titik sampling dilihat dari Google Earth and Google Maps ${ }^{\mathrm{TM}} 2011$ (Study area and sampling point as seen from Google Earth and Google Maps ${ }^{T M}$ 2011) 
kelimpahan dan distribusi paku cakar ayam pada plot pengamatan. Analisis ordinasi ini juga digunakan untuk mengidentifikasi pola asosiasi jenis paku cakar ayam dengan jenis lain yang tumbuh bersamanya berdasarkan data presence-absence yang didapatkan. Data kelimpahan paku cakar ayam kemudian juga dipadukan dengan data hasil pengukuran variabel mikroklimat untuk mendapatkan nilai korelasinya dengan menggunakan analisis Spearman bivariate correlation.

\section{HASIL DAN PEMBAHASAN}

Koridor jalan yang melintasi hutan diketahui mempengaruhi kondisi mikroklimat dan vegetasi di sepanjang tepi hutan yang berbatasan dengan jalan tersebut. Sebagian besar tepi jalan ini ditumbuhi oleh rasamala (Altingia excelsa). Sebagian hutan Bukit Pohen memang merupakan hutan yang dilindungi yang ditanami rasamala dengan usia tanam yang sama. Jenis pohon ini banyak ditanam terutama pada bagian terluar kawasan cagar alam serta pada daerah tepi yang berbatasan dengan jalan. Hasil pengukuran faktor lingkungan ditabulasikan dalam Tabel 1.

Secara umum kondisi mikroklimat di lokasi penelitian bervariasi. Terdapat perubahan nilai faktor lingkungan yang dihitung dari mulai tepi jalan (eksterior) hu- tan hingga masuk ke dalam (interior) hutan. Kondisi ini dapat dikatakan pula sebagai adanya gradien lingkungan. Pada beberapa parameter lingkungan, terdapat penurunan nilai seiring semakin masuknya plot sampling ke interior hutan. Intensitas cahaya berkurang dari sekitar 6771,7 menjadi 649,2 lux diikuti suhu udara dari sekitar $20^{\circ} \mathrm{C}$ menjadi $19^{\circ} \mathrm{C}$. Penurunan kedua parameter ini berbanding terbalik dengan peningkatan kelembaban udara relatif yang meningkat dari sekitar $80 \%$ menjadi $91,5 \%$ pada eksterior hutan. Dari segi lansekap topografi hutan, terdapat variasi kemiringan lahan atau slope antara $5^{\circ}-30^{\circ}$ serta ketinggian tempat atau altitude yang makin naik seiring semakin masuknya ke interior hutan, yaitu dari sekitar $1.500 \mathrm{~m}$ hingga $1.600 \mathrm{~m} \mathrm{dpl}$.

Dari hasil analisis ordinasi (Gambar 3) terlihat adanya perbedaan kelimpahan paku cakar ayam di lokasi studi. Ordinasi ini cukup bagus, terlihat dari rendahnya nilai 2D stress-nya $(0,09)$. Dalam hal komposisi vegetasi, dari letak ordinasi titik-titik sampling $\left(\mathrm{A}_{1}\right.$ s.d. $\mathrm{A}_{5}$ dan $\mathrm{B}_{1}$ s.d. $B_{5}$ ) yang menunjukkan pola tersebar (scatter) terlihat bahwa terdapat perbedaan komposisi vegetasi antar plot pengamatan, mulai dari tepi hutan atau bagian eks-terior ke dalam interior hutan. Hanya titik sampling pertama pada masing- masing transek saja yang terletak di eksterior

Tabel (Table) 1. Parameter lingkungan dan lansekap pada lokasi sampel di Bukit Pohen Cagar Alam Batukahu, Bali (Environmental and landscape parameters at sampling locations in Pohen Hill Batukahu Nature Reserve, Bali)

\begin{tabular}{cccccc}
\hline Plot & $\begin{array}{c}\text { Suhu } \\
(\text { Temperature }) \\
\left({ }^{\circ} \mathrm{C}\right)\end{array}$ & $\begin{array}{c}\text { Kelembaban relatif } \\
\text { Relative humidity })\end{array}$ & $\begin{array}{c}\text { Intensitas cahaya } \\
(\text { Light intensity }) \\
(\text { lux })\end{array}$ & $\begin{array}{c}\text { Kemiringan } \\
(\text { Slope }) \\
\left({ }^{\circ}\right)\end{array}$ & $\begin{array}{c}\text { Ketinggian } \\
(\text { Altitude }) \\
(\mathrm{m})\end{array}$ \\
\hline $\mathrm{A}_{1}$ & 20,0 & 80,0 & $6.771,7$ & 5,0 & $1.575,0$ \\
$\mathrm{~A}_{2}$ & 19,5 & 87,0 & $1.896,7$ & 5,0 & $1.578,0$ \\
$\mathrm{~A}_{3}$ & 20,0 & 87,0 & 502,0 & 15,0 & $1.587,0$ \\
$\mathrm{~A}_{4}$ & 19,0 & 91,5 & $1.390,0$ & 16,0 & $1.592,0$ \\
$\mathrm{~A}_{5}$ & 19,0 & 91,5 & $1.299,0$ & 30,0 & $1.600,0$ \\
$\mathrm{~B}_{1}$ & 19,5 & 78,5 & $16.387,5$ & 5,0 & $1.525,0$ \\
$\mathrm{~B}_{2}$ & 19,0 & 75,5 & $1.742,5$ & 5,0 & $1.530,0$ \\
$\mathrm{~B}_{3}$ & 18,5 & 87,5 & $1.269,7$ & 25,0 & $1.536,0$ \\
$\mathrm{~B}_{4}$ & 19,0 & 91,0 & $2.866,7$ & 25,0 & $1.551,0$ \\
$\mathrm{~B}_{5}$ & 18,0 & 95,5 & 649,2 & 35,0 & $1.575,0$ \\
\hline
\end{tabular}


hutan yang saling berdekatan, yang menandakan pada bagian eksterior hutan ini komposisi vegetasinya memiliki kemiripan atau hampir sama satu sama lain. Dalam hal kelimpahan, lingkaran hijau pada titik-titik sampling menandakan bahwa semakin besar diameter lingkaran, artinya kelimpahan paku cakar ayam juga semakin besar. Dapat dilihat bahwa secara umum kelimpahan paku cakar ayam bertambah saat plot pengamatan semakin masuk ke dalam hutan $\left(\mathrm{A}_{1} \rightarrow \mathrm{A}_{2} \rightarrow \mathrm{A}_{5}\right.$ dan $\mathrm{B}_{2} \rightarrow \mathrm{B}_{5}$ ).

Dari hasil analisis ordinasi NMDS, tampak bahwa kelimpahan terbesar paku cakar ayam terdapat pada plot pengamatan yang paling dalam (interior), baik pada transek pertama $\left(\mathrm{A}_{5}\right)$ maupun pada transek kedua $\left(\mathrm{B}_{5}\right)$. Hal ini menarik untuk diselidiki lebih jauh mengenai adakah faktor-faktor lingkungan yang turut mempengaruhi perbedaan kelimpahan tersebut. Hasil analisis korelasi Spearman antara beberapa faktor lingkungan terukur yang diamati dengan perbedaan kelimpahan paku cakar ayam disajikan pada Gambar 4.
Sebanyak tiga korelasi positif (kelembaban, slope, dan altitude) dan satu korelasi negatif diketahui dari hasil analisis (Gambar 4). Kelembaban berkorelasi positif dengan nilai korelasi (Spearman's rho) 0,3, sedangkan slope dan altitude memiliki nilai korelasi 0,2 dan 0,4. Dengan demikian diketahui dari hasil studi bahwa kelimpahan paku cakar ayam semakin meningkat seiring dengan semakin masuknya plot sampel ke arah interior hutan di mana terdapat peningkatan nilai faktor kelembaban dan ketinggian, serta pada lokasi yang memiliki nilai kelerengan yang agak curam sampai curam. Korelasi negatif dengan suhu (Spearman's rho $=-0,2$ ) menandakan bahwa dengan makin meningkatnya suhu udara, kelimpahan jenis ini semakin menurun. Hasil penelitian ini membuktikan secara kuantitatif dan empiris mengenai hasil temuan Setyawan (2009) yang menyatakan bahwa sebagian besar masyarakat di Nusantara mengetahui bahwa jenis-jenis paku cakar ayam biasanya terdapat pada lokasi yang lembab, basah, dan juga ditemukan di dekat jurang atau dekat tebing yang curam.

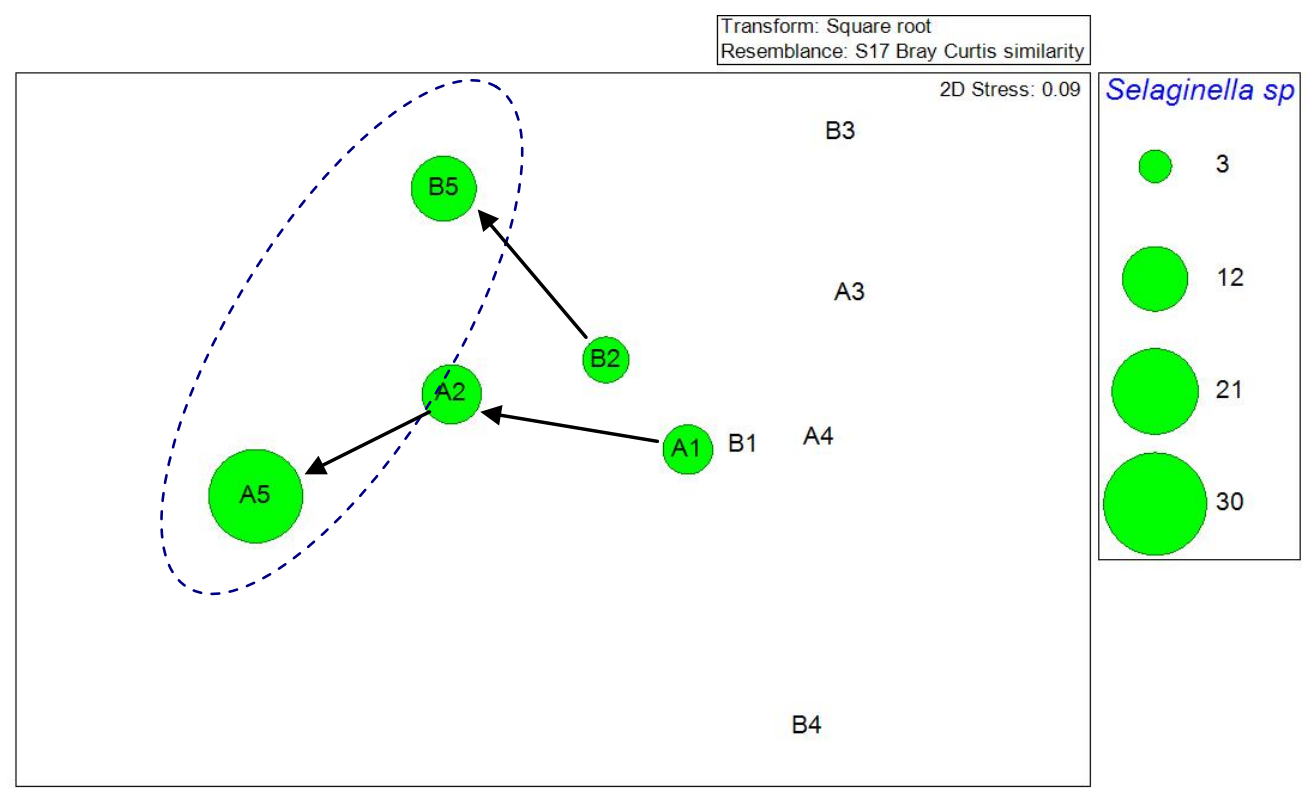

Gambar (Figure) 3. Hasil ordinasi NMDS $(2 D$ stress $=0,09)$ yang menunjukkan perbedaan dalam komposisi jenis di tiap plot sampel serta perubahan kelimpahan paku cakar ayam (Selaginella doederleinii) (NMDS ordination result $(2 D$ stress $=0.09)$ which shows species composition difference in each sample plot and change in abundance of spike-moss (Selaginella doederleinii) 

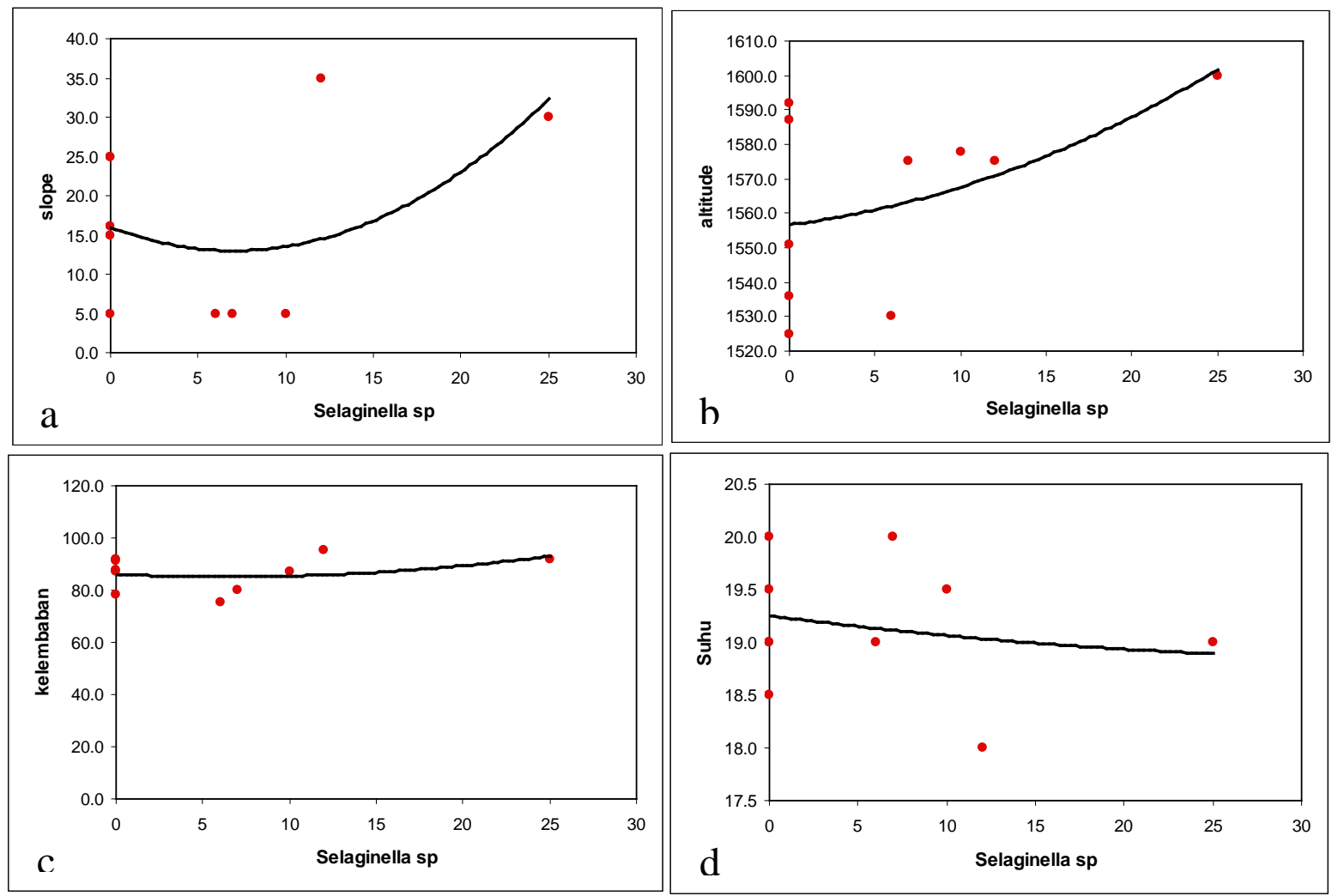

Gambar (Figure) 4. Hasil analisis Spearman bivariate correlation antara kelimpahan paku cakar ayam (Selaginella doederleinii) dengan beberapa faktor lingkungan yang diukur di lokasi sampling: (a) korelasi dengan kelerengan (Spearman's rho =0,2); (b) korelasi dengan ketinggian (Spearman's rho $=0,4$ ); (c) korelasi dengan kelembaban (Spearman's rho $=0,3$ ); dan (d) korelasi dengan suhu (Spearman's rho = -0,2) (Spearman bivariate correlation analysis result between abundance of spike-moss (Selaginella doederleinii) and several environmental factors at sampling location: (a) correlation with slope (Spearman's rho $=0.2$ ); (b) correlation with altitude (Spearman's rho $=0.4)$; (c) correlation with humidity (Spearman's rho = 0.3); and (d) correlation with temperature (Spearman's rho $=-0.2$ )

Selain berhubungan dengan faktor fisik atau abiotik, studi autekologi juga berupaya mengungkap hubungan jenis target dengan faktor biotik di habitat alaminya. Data presence-absence jenis digunakan untuk membuat suatu matriks kemiripan berdasarkan Bray-Curtis (similarity matrices) dan dibuat analisis ordinasinya. Gambar 5 memperlihatkan hasil analisis ordinasi NMDS untuk mengetahui asosiasi jenis pada lokasi sampel.

Terdapat delapan kluster asosiasi pada lokasi sampel. Kluster dengan anggota terbanyak adalah asosiasi antar jenis berhabitus pohon dengan enam anggota asosiasi yaitu seedling atau anakan dari Acronychia trifoliata - Litsea sp. - Breynia sp. - Podocarpus imbricatus - Syzygium sp. - Altingia excelsa; diikuti oleh kluster selanjutnya dengan lima anggota asosiasi yaitu antar jenis non pohon seperti Bidens biternata - Rubus sp. - Cyperus rotundus - Imperata cylindrica - Zingiber sp. Selain itu dijumpai pula asosiasi antar jenis yang berbeda habitus (pohon-non pohon) seperti tampak pada kluster Homalanthus gigantheus dengan Polygonum chinensis. Dari hasil analisis ini, paku cakar ayam diketahui berasosiasi dengan Oplismenus sp. Hal ini berarti bahwa pada lokasi sampel terdapat kecenderungan afinitas paku cakar ayam untuk hidup bersama dengan Oplismenus sp. yang kemungkinan mengindikasikan adanya interaksi di antara keduanya, baik berupa kompetisi ataupun fasilitasi. Namun demikian, untuk mengkonfirmasi bentuk interaksi ini diperlukan penelitian lebih lanjut.

Paku cakar ayam atau rane (Selaginella doederleinii) adalah jenis tumbuhan obat yang belum banyak dikenal dan dipergunakan secara meluas pemanfaatannya, 


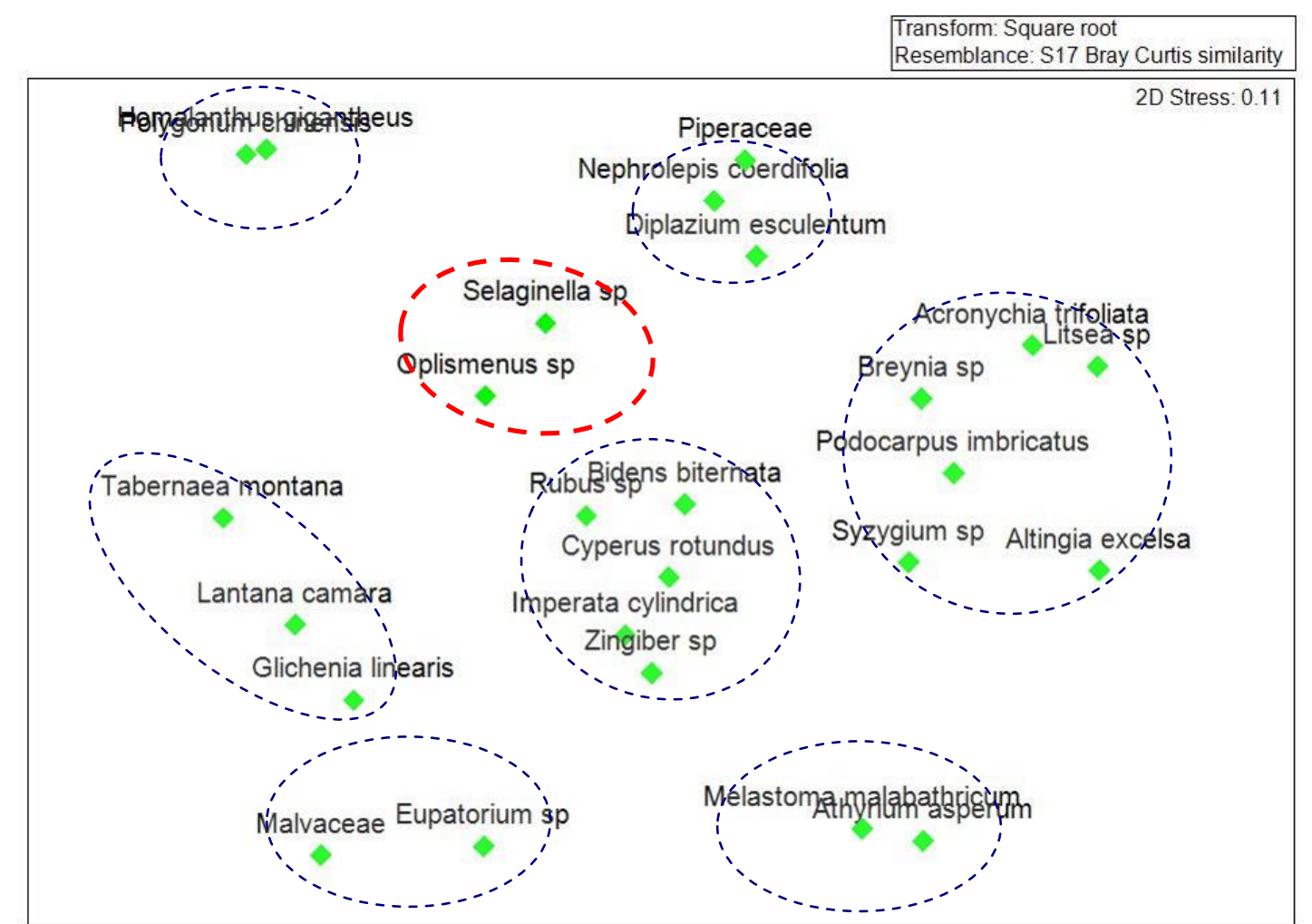

Gambar (Figure) 5. Hasil ordinasi NMDS (2D stress $=0,11)$ yang menunjukkan kluster asosiasi komunitas tumbuhan termasuk paku cakar ayam (Selaginella doederleinii) di lokasi sampling $($ NMDS ordination result $(2 D$ stress $=0.11)$ which shows association clusters of plant community including spike-moss (Selaginella doederleinii) at sampling locations)

baik secara tradisional maupun secara modern (Setyawan, 2009). Famili Selaginellaceae Reichb. hanya mempunyai satu genus yaitu Selaginella Pal. Beauv. yang terdiri dari 700-750 jenis. Di kawasan Malesia dan Nusantara, terdapat sekitar 200 jenis Selaginella (Tryon dan Tryon, 1982). Di Pulau Jawa, diperkirakan terdapat sekitar 24 jenis dengan lima jenis endemik. Dari jenis-jenis ini sebagian besar kemungkinan berada di ambang kepunahan (Setyawan, 2008). Studi autekologi adalah langkah awal yang diperlukan dalam upaya konservasi jenis Selaginella, baik secara in-situ maupun ex-situ. Dalam upaya konservasi ex-situ, studi autekologi dapat memberikan input yang sangat berharga dalam proses aklimatisasi dan sebagai dasar propagasi jenis Selaginella untuk dikembangkan, misalnya di kebun raya dan dikelola sebagai taman tematik maupun untuk dikembalikan ke habitatnya melalui program reintroduksi
(Sutomo, 2007; Sutomo et al., 2007; Sutomo \& Mukaromah, 2010).

\section{KESIMPULAN DAN SARAN}

\section{A. Kesimpulan}

Kelimpahan paku cakar ayam (Selaginella doederleinii Hieron) di habitat alaminya berkorelasi dengan faktor-faktor lingkungan yang terkait dengan mikroklimat dan lansekap, seperti kelembaban, temperatur, slope, dan altitude. Pada lokasi penelitian, gradien faktor lingkungan di sepanjang tepi ke interior hutan mempengaruhi kelimpahan paku cakar ayam, di mana jenis ini lebih banyak dijumpai pada interior hutan yang lembab dan basah dibandingkan pada tepi hutan yang relatif lebih kering.

\section{B. Saran}

Adanya asosiasi paku cakar ayam (Selaginella doederleinii Hieron) dengan 
Oplismenus sp. mengindikasikan adanya interaksi antara keduanya. Namun demikian, diperlukan penelitian lebih lanjut untuk mengkonfirmasi bentuk interaksi yang terjadi pada kedua jenis tumbuhan ini.

\section{DAFTAR PUSTAKA}

Anonim. (2005). Kawasan konservasi Provinsi Bali. Balai Konservasi dan Sumber Daya Alam Departemen Kehutanan Bali.

Backer, C.A. \& van den Brink, R.C.B. (1963). Flora of Java. Leiden: The Rijksherbarium.

Clarke, K.R. \& Gorley, R.N. (2005). PRIMER: plymouth routines in multivariate ecological research. Plymouth: PRIMER-E Ltd.

Dalimartha, S. (1999). Atlas tumbuhan obat Indonesia. Jakarta: Trubus Agriwidya.

Hutapea, J.R. (1999). Inventaris tanaman obat Indonesia. Jakarta: Departemen Kesehatan RI dan Badan Penelitian dan Pengembangan Kesehatan.

Nala, N. (1996). Usada Bali. Denpasar: PT. Upada Sastra.

Setyawan, A.D. (2008). Species richness and geographical distribution of Malesian Selaginella. $8^{\text {th }}$ seminary and congress of Indonesian Plant Taxonomy Association ("PTTI"). Bogor: Indonesian Plant Taxonomy Association ("PTTI").

Setyawan, A.D. (2009). Traditionally utilization of Selaginella: field research and literature review. Nusantara BIOSCIENCES 1, 146-158.

Sutomo. (2007). Usada Bali dalam perspektif konservasi Kebun Raya
“Eka Karya” Bali. Warta Kebun Raya, 15-18.

Sutomo. (2011). Cemara pandak (Dacrycarpus imbricatus (Blume) de Laub.) di kawasan bekas kebakaran hutan Bukit Pohen Cagar Alam Batukahu Bali. Jurnal Biologi Lingkungan Al-Kauniyah 5, 20-25.

Sutomo \& Darma, I.D.P. (2011). Vegetation analysis of Lake BuyanTamblingan forest areas Bali for its sustainability management. Bumi Lestari 11, 78-84.

Sutomo, Kurniawan, A., Pendit, I.M.R., Ardaka, I.M. \& Sudiatna, I.N. (2009). Koleksi tumbuhan obat usada Bali di Kebun Raya "Eka Karya" Bali. Bali: UPT Balai Konservasi Tumbuhan Kebun Raya "Eka Karya" Bali.

Sutomo \& Mukaromah, L. (2010). The autecology of purnajiwa (Euchresta horsfieldii (Lesch.) Benn., Fabaceae) in some areas of Tapak Hill Batukahu Nature Reserve Bali. Jurnal Biologi Universitas Udayana XIV, 24-28.

Sutomo, Mukaromah, L. \& Sandi, I.K. (2007). The "Usada Bali" medicinal plants in some areas of Buleleng, Bali. Seminar konservasi tumbuhan usada Bali dan peranannya dalam mendukung ekowisata. M. Siregar, H.M. Siregar, I.B.K. Arinasa, \& W.S. Lestari (eds.). UPT Balai Konservasi Tumbuhan Kebun Raya "Eka Karya" Bali-LIPI, Bali.

Tryon, R.M. \& Tryon, A.F. (1982). Fern and allied plants, with special reference to tropical America. New York: Springer. 